\title{
REVIEWS
}

\section{Failure to Follow-Up Test Results for Ambulatory Patients: A Systematic Review}

\author{
Joanne L. Callen, PhD, Johanna I. Westbrook, PhD, Andrew Georgiou, PhD, and Julie Li, BAppSc \\ (HIM) (Hons 1)
}

Centre for Health Systems and Safety Research, Faculty of Medicine, The University of New South Wales, Sydney, NSW, Australia.

BACKGROUND: Serious lapses in patient care result from failure to follow-up test results.

OBJECTIVE: To systematically review evidence quantifying the extent of failure to follow-up test results and the impact for ambulatory patients.

DATA SOURCES: Medline, CINAHL, Embase, Inspec and the Cochrane Database were searched for Englishlanguage literature from 1995 to 2010.

STUDY SELECTION: Studies which provided documented quantitative evidence of the number of tests not followed up for patients attending ambulatory settings including: outpatient clinics, academic medical or community health centres, or primary care practices.

DATA EXTRACTION: Four reviewers independently screened 768 articles.

RESULTS: Nineteen studies met the inclusion criteria and reported wide variation in the extent of tests not followed-up: $6.8 \%(79 / 1163)$ to $62 \%(125 / 202)$ for laboratory tests; $1.0 \%(4 / 395)$ to $35.7 \%(45 / 126)$ for radiology. The impact on patient outcomes included missed cancer diagnoses. Test management practices varied between settings with many individuals involved in the process. There were few guidelines regarding responsibility for patient notification and follow-up. Quantitative evidence of the effectiveness of electronic test management systems was limited although there was a general trend towards improved test follow-up when electronic systems were used.

LIMITATIONS: Most studies used medical record reviews; hence evidence of follow-up action relied upon documentation in the medical record. All studies were conducted in the US so care should be taken in generalising findings to other countries.

CONCLUSIONS: Failure to follow-up test results is an important safety concern which requires urgent attention. Solutions should be multifaceted and include: policies relating to responsibility, timing and process of notification; integrated information and communication technologies facilitating communication; and consideration of the multidisciplinary nature of the process and the role of the patient. It is essential that evaluations of interventions are undertaken and

Received July 29, 2011

Revised September 28, 2011

Accepted November 4, 2011

Published online December 20, 2011 solutions integrated into the work and context of ambulatory care delivery.

KEY WORDS: patient safety; test result follow-up; medical errors; primary care; quality improvement.

J Gen Intern Med 27(10):1334-48

DOI: $10.1007 / \mathrm{s} 11606-011-1949-5$

(C) The Author(s) 2011. This article is published with open access at Springerlink.com

\section{INTRODUCTION}

Failure to follow up test results is a critical safety issue which has been identified as a major problem in ambulatory settings. ${ }^{1-4}$ The practices and processes currently used are varied and unsystematic ${ }^{2,5}$ and physicians $s^{6,7}$ and patients ${ }^{8,9}$ acknowledge that this needs to improve. The testing process in ambulatory settings is complex and can be divided into three broad phases, pre-analytic, analytic and post-analytic (Fig. 1), each involving multiple steps and multiple personnel including clinicians, patients, office and laboratory staff. $^{10}$

Most primary care practices are not using electronic health records,${ }^{11}$ and most are communicating with multiple laboratories often not electronically connected..$^{12}$ Increased volumes of tests and the time consuming nature of test follow-up places further pressures on physicians. ${ }^{6,13,14}$ Failure to followup can lead to missed or delayed diagnoses which impact on patient care ${ }^{13,15-17}$ and can also have medico-legal implications for health services and health professionals. ${ }^{18-21}$

Without knowledge of the size of the problem, many clinicians may underestimate its extent and therefore fail to take any action to improve the process. ${ }^{22}$ Feedback on medical errors is essential to negate overconfidence in decision making in relation to diagnostic accuracy. ${ }^{22-25}$ Ambulatory settings pose specific challenges for effective test management in addition to many of those present in acute care settings. ${ }^{26}$ There have been no systematic reviews in this setting, and therefore the aim of this paper was to review evidence which quantifies the size and impact on patient outcomes of failure to follow-up test results for ambulatory patients. 


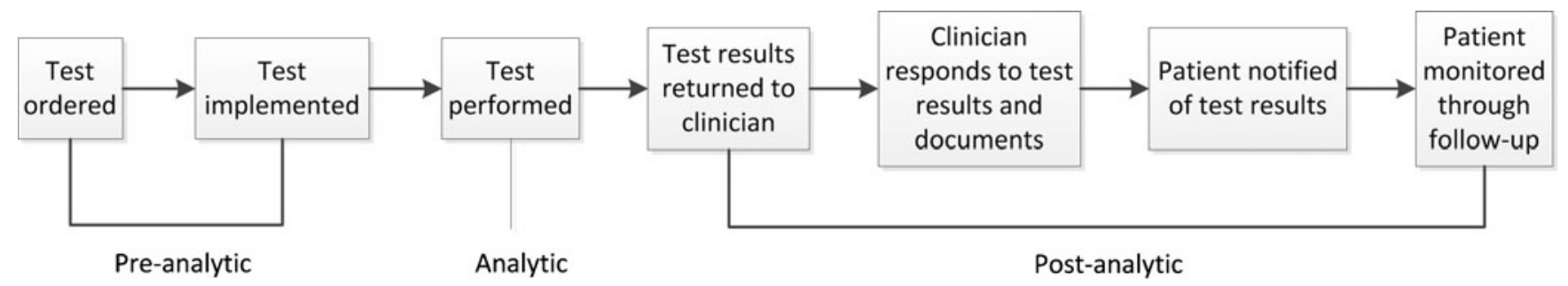

Figure 1. Conceptual framework of the testing process (Source Hickner et al. 2008, p.195). ${ }^{10}$

\section{METHODS}

\section{Data Sources and Searches}

Medline, CINAHL, Embase, Inspec and the Cochrane Database were systematically searched for English language articles published between 1995 and November 2010 which quantified diagnostic tests not followed-up (Fig. 2). Search terms were identified from keyword lists of core articles related to the topic. Reference lists of articles which met the inclusion criteria were hand searched. A web search using the Google Scholar search engine was completed to locate un-indexed publications.

\section{Study Selection}

Included were studies which quantified failure to follow-up laboratory and radiology tests for patients attending ambulatory settings including: outpatients, patients treated at academic medical and community health centres and attending primary care practices. Failure to follow-up a test result was defined as the ordering physician or another provider neglecting to document follow-up action(s) relating to a test result. Excluded were studies reporting physicians' or patients' perceived rates of failure, time from placement of test order to treatment, analysis and reporting of test follow-up for inpatients and outpatients combined ${ }^{27,28}$ and studies on individual patients.

\section{Data Extraction}

Four reviewers (JC, AG, JL, JW) each independently reviewed all articles for inclusion. Discrepancies among reviewers were resolved by discussion until a consensus was reached. Data extracted included: test type, indication of failure to follow-up, systems used, extent and patient outcomes.

\section{RESULTS}

The literature search yielded 768 references (including four from hand searching) from which 19 articles were eligible (Table 1).

\section{Study Characteristics}

All studies were conducted in the United States. The majority of study designs used retrospective medical record reviews $(\mathrm{n}=16)^{2,29-43}$ to provide documentary evidence of test follow-up. Other methods were: retrospective linkage of databases $(n=1),{ }^{44}$ retrospective review of malpractice claims for missed or delayed diagnoses $(n=1),{ }^{45}$ and a prospective longitudinal medical record review $(n=1) .{ }^{46}$ Most studies focused on lack of follow-up of abnormal laboratory tests only $(n=11){ }^{29,32,35-38,41-45}$ Four studies investigated lack of abnormal radiology follow-up only $^{31,39,40,46}$ and another four studies included lack of follow-up for both laboratory and radiology test results. ${ }^{2,30,33,34}$

\section{Extent of Failure to Follow-up}

There was wide variation in the rates of missed abnormal laboratory results ranging from $6.8 \%(79 / 1163)^{41}$ of alerts displayed through a computerised provider order entry system which were not followed-up within 30 days to $62 \%(125 / 202)$ of abnormal glucose tests not followed-up. ${ }^{32}$ Similarly, for abnormal radiology, lack of follow-up ranged from $1.0 \%(4 / 395)^{31}$ of patients with suspected malignancy to $11 \%(131 / 1196)$ of critical imaging alerts. ${ }^{40}$ The two studies on mammograms reported $11 \%(9 / 82)^{30}$ and $35.7 \%$ $(45 / 126)^{46}$ with no evidence of patient follow-up. Even studies which focused on the same diagnostic tests showed a broad range in the extent of lack of follow-up: glucose testing ${ }^{32,35,44}$; abnormal $\mathrm{FOBT}^{29,43}$ and $\mathrm{TSH}^{41,42}$

\section{Impact on Patient Outcomes}

The impact of missed test results on patient outcomes were reported in seven of the 19 studies. ${ }^{29,31,32,38,40,42,45}$ Missed cancer diagnoses were reported in four. ${ }^{29,31,40,45}$ Other reported outcomes were increased visits to hospital as a result of hyperkalaemia related to missed abnormal serum potassium levels ${ }^{38}$ and adverse drug events related to insufficient supplementation with levothyroxine due to missed follow-up of abnormal TSH results. ${ }^{42}$ Patients 


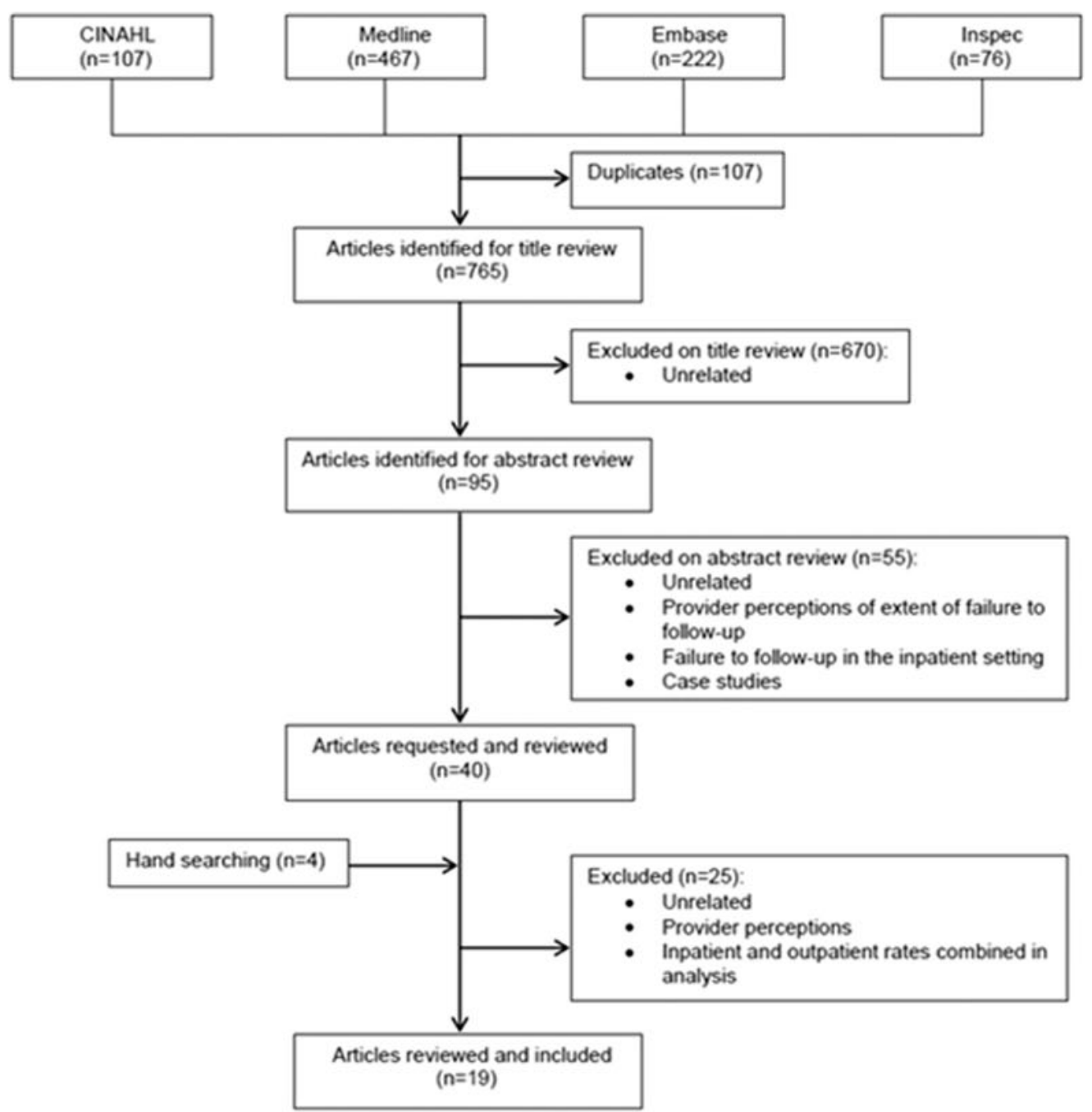

1. Ambulatory care

2. Ambulatory care facilities

3. Outpatients

4. Primary health care

5. Family practice

6. Medical errors

7. Diagnostic tests, routine

8. Diagnostic imaging

9. Continuity of patient care

10. Error

11. Test result

12. Missed result

13. Missed diagnosis

14. Follow up

15. Incidental findings

16. Delayed diagnosis

17. 1 or $\sim 5$

18. 6 or $\sim 10$

19. 11 or $\sim 16$

20. 17 and 18 and 19

"denotes explosion of subject heading in some databases

denotes partial explosion of subject heading in some databases

'Also searched as keywords

Words in bold are MeSH terms

Figure 2. Search flow for failure to follow-up test results for ambulatory patients, including keywords and MeSH terms used in search process. 
who received appropriate follow-up of diabetes screening were more likely to have been scheduled for follow-up appointments than those who were not (92\% versus $66 \%$, $\mathrm{P}=0.001$ ) and were also more likely to have kept the appointments $(90 \%$ versus $58 \%, \mathrm{P}=0.001) .{ }^{32}$

\section{People and Policies}

Test management involves information communication between many individuals across care settings including: physicians, nurses, clerks, laboratory staff, and patients. Studies showed that test follow-up practices varied between individuals $^{34,37}$ and practice settings. ${ }^{33}$ Individuals other than physicians were involved in the test follow-up phase, including nurses and practice managers. ${ }^{29-31,33,34}$

Several studies reported an absence of guidelines regarding who has responsibility, and how and when to notify patients of results. ${ }^{2,29,33,34}$ Singh et al. in $2007^{39}$ showed lower rates of missed abnormal imaging results than similar studies which they concluded was associated with having standardized processes and procedures for abnormal test result follow-up in combination with an electronic test result notification system.

\section{Systems Used for the Test Management Process}

Those studies which described the systems used to deliver test results to physicians and how follow-up was documented ranged from paper-based medical records with test results delivered in hard copy $^{2,29,30,33,34}$ to electronic medical records (EMR) with results transmitted electronically, ${ }^{2,33,34,39-41}$ or a combination of paper-based medical records and electronic or part-electronic test management systems. ${ }^{2,31,37,38}$ Evidence of the effectiveness of electronic test management systems to reduce missed follow-up was limited to five studies. ${ }^{2,34,39-41}$ Although these evaluations were not pre/post control studies they showed a general trend towards improved test follow-up in ambulatory settings which used electronic systems.

Three studies evaluated whether an automatic alert system for notification of abnormal results resulted in timely follow-up of radiology ${ }^{39,40}$ and laboratory tests. ${ }^{41}$ Even though these studies have some features which may limit generalisability, due to the unique characteristics of the Veterans Affairs (VA) population (predominantly male veterans), the home-grown EMR VA system, and the lack of pre EMR data for comparison, results showed that the rates of loss to follow-up appeared lower than those reported in sites that do not use information technology. However, even with the sophisticated electronic alert system in place a proportion of results were still missed: $4 \%(45 / 1017)$ of critical imaging results ${ }^{39} ; 11 \%$ of alerts for abnormal imaging (acknowledged and unacknowledged) ${ }^{40}$; and $6.8 \%$ of specified abnormal laboratory tests. ${ }^{41}$ Interestingly, in the latter study Singh et al. ${ }^{41}$ found that $10.2 \%$ of alerts were unacknowledged by physicians (provider did not click on and open the message within two weeks of transmission) and timely follow-up was statistically not different for acknowledged and unacknowledged alerts $(6.4 \%$ versus $10.1 \%$; $\mathrm{P}=0.13)$.

Having test management processes supported by hybrid paper and electronic systems has also been shown to create problems with test follow-up. Casalino et al. reported that the use of a partial electronic medical record (paper based progress notes and electronic tests or vice versa) was associated with higher follow-up failure rates compared to relying entirely on paper-based systems (OR $1.92 ; \mathrm{P}=0.03$ ) or compared to having a complete electronic record that included both progress notes and test results (OR 2.37; $\mathrm{P}=0.007){ }^{2}$ Another study found that results managed in the EMR were significantly better documented than those with paper (40\%, 33/82, compared to $64 \%, 57 / 88, \mathrm{p}=0.001)^{34}$ and documentation of followup actions has been shown to impact positively on test management. ${ }^{38,46}$

\section{DISCUSSION}

\section{Extent and Impact on Patient Outcomes}

Failure to follow-up test results occurs frequently in ambulatory settings and evidence of its impact demonstrates that it is an important patient safety issue which needs urgent attention. There was wide variability reported regarding the extent of the problem ranging from $6.8 \%{ }^{41}$ to $62 \%{ }^{32}$ for missed laboratory tests and $1.0 \%{ }^{31}$ to $35.7 \%{ }^{46}$ for radiology. This variability was also present in studies which examined follow-up of the same test types which highlights the heterogeneity of the studies and the complexity of the problem. ${ }^{29,32,35,41-44}$ Similar results relating to extent and variability of test follow-up have previously been reported for inpatients $(20.04 \%-61.9 \%)$ and patients attending emergency departments $(1 \%-$ $75 \%){ }^{26}$ Impact on ambulatory patient outcomes were considerable and included missed cancer diagnoses ${ }^{29,31,40,45}$ underpinning the urgent nature of the problem and the need to evaluate solutions.

Given that all studies were conducted in the US care should be taken in generalising the findings to other 
countries although anecdotal evidence suggests that test management practices are similar worldwide. Eight of the 19 studies were based in three sites and undertaken by the same lead researcher in each site. ${ }^{33,34,36-41}$ A limitation of 12 of 19 studies was that they were conducted in single sites. However the six studies which included multiple primary care practices with large samples showed consistently high rates of lack of follow-up..$^{2,30,32-34,46}$ Most studies used retrospective medical record reviews which may result in an overestimation of the problem as some results could have been followed-up even though the physician failed to document the action. It is possible that there may be some publication bias whereby papers which reported higher rates of missed follow-up of test results are more likely to be published than studies which found low rates.

Missed test results in ambulatory settings are attributable to multiple factors including: the paucity of governance principles related to test management; the lack of integrated information systems around test management; the multidisciplinary nature of test management processes, and the need to consider the role of the patient in test result follow-up.

\section{Test Management Governance Principles}

There are few standard policies or procedures for test result management in the literature or within ambulatory practice organisations. This contributes to the variability of responsibility and the diversity of work practices around each of the steps in the test management process. ${ }^{2,29,33,34,39,40}$ Singh et al. ${ }^{39}$ concluded that if policies and procedures were in place, combined with the use of an electronic alert notification of abnormal radiology, then follow-up of results would be improved. However they found that missed results were not eliminated altogether ${ }^{39}$ indicating the complex nature of the problem and the need to consider a combination of interventions.

The lack of clear lines of responsibility for follow-up is further complicated by the number of people involved. Blurred lines of responsibility were evident in one study which evaluated the practice of dual-alert notification: this measure was adopted as a safeguard and entailed communicating the alert of an abnormal radiology result to two recipients, for example the hospital doctor who ordered the test and the primary care physician. ${ }^{40}$ Results showed that dual-alert notification significantly increased the odds that the alert would not be read and receive timely follow-up action (OR, 1.99; 95\% CI, 1.06-3.48). ${ }^{40}$ This highlights the need for explicit guidelines regarding responsibility and timeframes for follow-up.

\section{The Role of Information and Communication Technology in the Process}

Although studies of evidence regarding the link between EHRs and ambulatory quality of care have shown mixed results, ${ }^{47-51}$ a number have shown that information and communication technology (ICT) can play an important role in ensuring a safer and more systematic test management process. ${ }^{1,52,53}$ The five evaluations of the impact of ICT on missed test results, included in the review, provided evidence of a favourable trend towards reduced missed results. ${ }^{2,34,39-41}$ The use of ICT facilitates communication flow between individuals across care settings and has been shown to improve documenta$\operatorname{tion}^{38,46}$ all of which are crucial for the test management process. Other studies have shown that ICT can support and enhance the test management process ${ }^{14,54-57}$ with acknowledgement of receipt of results and documentation of follow-up action and patient notification recorded in an EMR which can be securely accessed by multiple health professionals.

Timely communication is vital and can be particularly challenging for ambulatory patients given the many individuals and settings involved. Information transfer about tests ordered and results received can have multiple points of communication breakdown: between inpatient and outpatient settings ${ }^{16,36}$; between laboratories and physicians ${ }^{58,59}$; between physicians and other member of their team ${ }^{33,34}$; and between physicians and patients. ${ }^{9,60}$ Electronic systems are an essential component of any solutions, however, they need to be integrated into the context of ambulatory settings and the way health professionals work. ${ }^{61,62}$ Financial issues are also considered to be a key barrier to primary care physicians' use of EHRs and financial incentives will be a key lever for improving uptake. $^{11}$

Technological solutions are not the entire answer as studies show that even with the use of an EMR with computerised notification of abnormal results using an alert every time the provider logs-on, abnormal results can still be missed. ${ }^{39-41}$ Even though physicians can electronically acknowledge that they have opened an alert message this does not necessarily indicate they have read and acted upon the abnormal result. ${ }^{41}$ Appropriate followup requires the physician to review the result, communicate this to the patient, decide on an appropriate plan and discuss this with the patient and help them with that follow-up plan. ${ }^{46}$ 
Electronic discharge summaries have been shown to improve quality and timeliness of information including test results. ${ }^{63}$ However, there can also be problems as electronic discharge summaries may not always reach the family doctor ${ }^{64}$ and may not include all the necessary clinical information required for the ongoing treatment of the patient. ${ }^{65,66}$ There can also be an overreliance on ICT. One study reported that staff who used an EHR believed that electronically reported results did not get lost and were unaware that several tasks still depended on individuals. ${ }^{33}$ Thus, even with an EHR there can still be weaknesses in test tracking. ${ }^{56}$

\section{Multidisciplinary Nature of Laboratory and Radiology Test Management Processes}

Test result follow-up and patient notification in ambulatory settings are generally undertaken by the physician treating the patient, with involvement of other physicians, nurses, laboratories, and practice managers. A number of studies recommend the need to take account of the multidisciplinary nature of the test management process and include not just the physician who ordered the test but other ambulatory practice staff $^{30,40}$ and also laboratory staff, ${ }^{67}$ in the design of solutions.

The involvement of nurses in the test notification process is evident in a number of studies ${ }^{29,31,33,34,37}$ and in busy ambulatory settings, where follow up of results is time consuming, ${ }^{13,14}$ this would seem to be a valuable approach. Nurses were reported as having a positive impact in one study where there was no significant difference between physicians and nurse practitioners in appropriate documentation of follow-up $(p=0.61){ }^{31}$ Studies have shown that documentation was associated with the delivery of appropriate ${ }^{46}$ and with timely follow-up of test results. ${ }^{38}$ Clerical staff in ambulatory settings can also assist in the follow-up of test results particularly in relation to ensuring systems are in place to alert physicians to results returned from laboratories and in the patient notification stage of the process. ${ }^{33}$

An innovative work practice change is the suggestion that radiology staff should become more involved in the patient test notification process. ${ }^{67,68}$ The process of direct patient notification by the radiologist has been described by one Imaging Service in the US whereby patients' are given a card on arrival asking if they would like to receive preliminary results of their examination. ${ }^{69}$ If the patient agrees the radiologist documents the preliminary results on the card which is given to the patient before they leave the Imaging Centre. ${ }^{69}$ Currently there are guidelines for direct communication of critical imaging findings by radiology staff to ordering physicians. ${ }^{70}$ However, problems arise in ensuring critical results are communicated to the appropriate person. ${ }^{16,31,71}$ Singh et al. ${ }^{40}$ found that verbal communication by radiology staff in addition to electronic communication of results strongly predicted timely response and follow-up, however this was probably because the radiologist called only for life threatening findings. Solutions which acknowledge the inter-dependence between physicians, nurses, and radiology/laboratory staff are important to ensure the safe communication of abnormal test results. ${ }^{72}$

\section{The Role of the Patient in Test Result Follow-up}

There have been suggestions that patients can play a role in detecting and preventing medical errors ${ }^{73}$ and could therefore have an enhanced role in the test result follow-up process. $^{27-29}$ Direct notification of test results to patients could serve as a safety net for providers and empower patients to be partners in their care. ${ }^{8,9}$ It is possible for electronic systems, linked to test result databases, to generate automatic letters, email or telephone messages to notify patients directly of positive and negative test results ${ }^{9}$ or to allow patients' direct access to results via a patient portal. ${ }^{74}$

The issue of direct patient notification however, is complex and many factors need to be considered. Physicians have expressed concerns including: whether an abnormal result will alarm a patient unnecessarily; receipt of an avalanche of contact from worried patients; practice variations in timing of patient notification; malpractice risks; and an increase in unreimbursed tasks. ${ }^{74}$ There are few published studies in this area, however, a feasibility study to introduce on-line laboratory results to patients in two primary care practices with 10 physicians reported that physicians had no increase in messages from their patients about inconsequential results showing that fears of unnecessary patient alarm may be unwarranted. $^{74}$ If all patients are directly notified of their test results, they need to be able to read and understand the result and its implications. ${ }^{30}$ Patient understanding of test results could be enhanced by access to relevant online information sources with one study reporting $50 \%$ of patients who viewed results via a patient portal accessed reference information linked to the result. ${ }^{74}$

Whether patients hear their results verbally or receive them in hard copy can also impact on their understanding and the emotional state of patients receiving significant results may also impair their ability to digest information provided verbally. ${ }^{75,76}$ Poon et al. ${ }^{46}$ found that a significant proportion of women whose physician documented that they had discussed the test result with the patient did not recall the discussion, highlighting the need for patients to have a written record of their results. Direct access to results via patient portals where patients could print a copy of the result would ensure they had an accurate hard-copy of the result which could be used as a memory aid. It is now a US FDA requirement under the Mammography Quality Standards Act (MQSA 2004) that a summary of the written report in terms understandable by a layperson is sent directly to the patient within 30 days, ${ }^{77}$ however studies have shown that giving 
patients their results is not in itself enough to ensure that patients follow-up on the result. ${ }^{46,78}$ Physicians need to have an active role in follow-up to ensure the plans are understood by patients. Further work needs to be undertaken in this area to test the feasibility and effectiveness of strategies which enable patients to receive their test results automatically.

\section{CONCLUSION}

There are significant safety issues in the management of laboratory and radiology test results for ambulatory patients. Studies show that factors associated with failure to followup test results in ambulatory settings are complex and often it is a combination of elements, systems, people, organisational factors and work practices interacting that leads to important results being missed. This concords with patient safety research which has progressed to acknowledge the multi-factorial nature of medical errors and the need to address people and system factors if improvements are to be realised. $^{79-81}$ Solutions need to be multipronged and include: explicit policies, procedures and responsibilities for test follow-up; consideration of the role of others in the process including the patient and laboratory and radiology staff; evaluation of ICT solutions; and integration of solutions into the work practices of health professionals and into the context of health care delivery.

Acknowledgements: This study is part of an Australian Research Council Linkage Grant (LP0989144) funded project to investigate the use of information and communication technologies to support effective work practice innovation in the health sector. The authors have no relevant financial interest in this manuscript.

Conflicts of Interest: None disclosed.

Open Access: This article is distributed under the terms of the Creative Commons Attribution Noncommercial License which permits any noncommercial use, distribution, and reproduction in any medium, provided the original author(s) and source are credited.

Corresponding Author: Joanne L. Callen, PhD; Centre for Health Systems and Safety Research, Faculty of Medicine, The University of New South Wales, Sydney, NSW 2052, Australia (e-mail: j.callen@unsw.edu.au).

\section{REFERENCES}

1. Hickner JM, Fernald DH, Harris DM, Poon EG, Elder NC, Mold JW. Issues and initiatives in the testing process in primary care physician offices. Jt Comm J Qual Patient Saf. 2005;31(2):81-9.

2. Casalino LP, Dunham D, Chin MH, Bielang R, Kistner EO, Karrison TG, et al. Frequency of failure to inform patients of clinically significant outpatient test results. Arch Intern Med. 2009;169(12):1123-9.

3. World Alliance for Patient Safety. World Health Organisation. Summary of the Evidence on Patient Safety: Implications for Research. In: Jha A, ed; 2008:1-118.

4. Schiff GD. Getting Results-Reliably Communicating and Acting on Critical Test Results: Joint Commission Resources; 2006.
5. Elder NC, Graham D, Brandt E, Dovey S, Phillips P, Ledwith J, et al. The Testing Process in Family Medicine: Problems Solutions and Barriers as Seen by Physicians and Their Staff. A study of the American Academy of Family Physicians' National Research Network. J Patient Saf. 2006;2 (1):25-32.

6. Boohaker EA, Ward RE, Uman JE, McCarthy BD. Patient notification and follow-up of abnormal test results. A physician survey. Arch Intern Med. 1996;156(3):327-31.

7. Murff HJ, Gandhi TK, Karson AK, Mort EA, Poon EG, Wang SJ, et al. Primary care physician attitudes concerning follow-up of abnormal test results and ambulatory decision support systems. Int J Med Inform. 2003;71(2-3):137-49.

8. Meza JP, Webster DS. Patient preferences for laboratory test results notification. Am J Manag Care. 2000;6(12):1297-300.

9. Keren R, Muret-Wagstaff S, Goldmann DA, Mandl KD. Notifying emergency department patients of negative test results: pitfalls of passive communication. Pediatr Emerg Care. 2003;19(4):226-30.

10. Hickner J, Graham DG, Elder NC, Brandt E, Emsermann CB, Dovey $\mathbf{S}$, et al. Testing process errors and their harms and consequences reported from family medicine practices: a study of the American Academy of Family Physicians National Research Network. Qual Saf Health Care. 2008;17(3):194-200.

11. Bates DW. Physicians and ambulatory electronic health records. Health Aff (Millwood). 2005;24(5): 1180-9.

12. Elder NC, Hickner J, Graham D. Quality and safety in outpatient laboratory testing. Clin Lab Med. 2008;28(2):295-303. vii.

13. Poon EG, Gandhi TK, Sequist TD, Murff HJ, Karson AS, Bates DW. "I wish I had seen this test result earlier!": Dissatisfaction with test result management systems in primary care. Arch Intern Med. 2004;164 (20):2223-8.

14. Poon EG, Wang SJ, Gandhi TK, Bates DW, Kuperman GJ. Design and implementation of a comprehensive outpatient Results Manager. J Biomed Inform. 2003;36(1-2):80-91.

15. Wahls TL, Cram PM. The frequency of missed test results and associated treatment delays in a highly computerized health system. BMC Fam Pract. 2007;8:32.

16. Roy CL, Poon EG, Karson AS, Ladak-Merchant Z, Johnson RE, Maviglia SM, et al. Patient safety concerns arising from test results that return after hospital discharge. Ann Intern Med. 2005;143(2):121-8.

17. Gandhi TK. Fumbled handoffs: one dropped ball after another. Ann Intern Med. 2005; 142(5):352-8.

18. Bird S. Missing test results and failure to diagnose. Aust Fam Physician. 2004;33(5):360-1.

19. Berlin L. Malpractice and radiologists. AJR Am J Roentgenol. 1980;135 (3):587-91.

20. Berlin L. Malpractice issues in radiology: res ipsa loquitur. AJR Am J Roentgenol. 2009;193(6): 1475-80.

21. Potchen EJ, Bisesi MA, Sierra AE, Potchen JE. Mammography and malpractice. AJR Am J Roentgenol. 1991;156(3):475-80.

22. Graber M. Diagnostic errors in medicine: a case of neglect. Jt Comm J Qual Patient Saf. 2005;31(2):106-13.

23. Leape LL. Error in medicine. JAMA. 1994;272(23):1851-7.

24. Parker D, Lawton R. Psychological contribution to the understanding of adverse events in health care. Qual Saf Health Care. 2003;12(6):453-7.

25. Hodges B, Regehr G, Martin D. Difficulties in recognizing one's own incompetence: novice physicians who are unskilled and unaware of it. Acad Med. 2001;76(10 Suppl):S87-9.

26. Callen J, Georgiou A, Li J, Westbrook JI. The safety implications of missed test results for hospitalised patients: a systematic review. BMJ Qual Saf. 2011;20(2):194-9.

27. Cram P, Rosenthal GE, Ohsfeldt R, Wallace RB, Schlechte J, Schiff GD. Failure to recognize and act on abnormal test results: the case of screening bone densitometry. Jt Comm J Qual Patient Saf. 2005;31(2):90-7.

28. Schiff GD, Kim S, Krosnjar N, Wisniewski MF, Bult J, Fogelfeld L, et al. Missed hypothyroidism diagnosis uncovered by linking laboratory and pharmacy data. Arch Intern Med. 2005;165(5):574-7.

29. Chen ZJ, Kammer D, Bond JH, Ho SB. Evaluating follow-up of positive fecal occult blood test results: lessons learned. J Healthc Qual: Promot Excell Healthc. 2007;29(5): 16 .

30. Chen ET, Eder M, Elder NC, Hickner J. Crossing the finish line: followup of abnormal test results in a multisite community health center. J Natl Med Assoc. 2010;102(8):720-5.

31. Choksi VR, Marn CS, Bell Y, Carlos R. Efficiency of a semiautomated coding and review process for notification of critical findings in diagnostic imaging. AJR Am J Roentgenol. 2006;186(4):933-6. 
32. Ealovega MW, Tabaei BP, Brandle M, Burke R, Herman WH. Opportunistic screening for diabetes in routine clinical practice. Diabetes Care. 2004;27(1):9-12.

33. Elder NC, McEwen TR, Flach JM, Gallimore JJ. Management of test results in family medicine offices. Ann Fam Med. 2009;7(4):343-51.

34. Elder NC, McEwen TR, Flach J, Gallimore J, Pallerla H. The management of test results in primary care: does an electronic medical record make a difference? Fam Med. 2010;42(5):327-33.

35. Kern LM, Callahan MA, Brillon DJ, Vargas M, Mushlin AI. Glucose testing and insufficient follow-up of abnormal results: a cohort study. BMC Health Serv Res. 2006;6:87.

36. Moore C, Wisnivesky J, Williams S, McGinn T. Medical errors related to discontinuity of care from an inpatient to an outpatient setting. J Gen Intern Med. 2003; 18(8):646-51.

37. Moore CR, Lin JJ, O'Connor N, Halm EA. Follow-up of markedly elevated serum potassium results in the ambulatory setting: implications for patient safety. Am J Med Qual. 2006;21(2):115-24.

38. Moore C, Lin J, McGinn T, Halm E. Factors associated with time to follow-up of severe hyperkalemia in the ambulatory setting. Am J Med Qual. 2007;22(6):428-37.

39. Singh H, Arora HS, Vij MS, Rao R, Khan MM, Petersen LA. Communication outcomes of critical imaging results in a computerized notification system. J Am Med Inform Assoc. 2007;14(4):459-66.

40. Singh H, Thomas EJ, Mani S, Sittig D, Arora H, Espadas D, et al. Timely follow-up of abnormal diagnostic imaging test results in an outpatient setting: are electronic medical records achieving their potential? Arch Intern Med. 2009;169(17):1578-86.

41. Singh H, Thomas EJ, Sittig DF, Wilson L, Espadas D, Khan MM, et al. Notification of abnormal lab test results in an electronic medical record: do any safety concerns remain? Am J Med. 2010;123(3):238-44.

42. Stelfox HT, Ahmed SB, Fiskio J, Bates DW. An evaluation of the adequacy of outpatient monitoring of thyroid replacement therapy. J Eval Clin Pract. 2004;10(4):525-30.

43. Etzioni DA, Yano EM, Rubenstein LV, Lee ML, Ko CY, Brook RH, et al. Measuring the quality of colorectal cancer screening: the importance of follow-up. Dis Colon Rectum. 2006;49(7):1002-10.

44. Edelman D. Outpatient diagnostic errors: unrecognized hyperglycemia Eff Clin Pract. 2002;5(1):11-6.

45. Gandhi TK, Kachalia A, Thomas EJ, Puopolo AL, Yoon C, Brennan TA, et al. Missed and delayed diagnoses in the ambulatory setting: a study of closed malpractice claims. Ann Intern Med. 2006;145(7):488-96.

46. Poon EG, Haas JS, Louise Puopolo A, Gandhi TK, Burdick E, Bates DW, et al. Communication factors in the follow-up of abnormal mammograms. J Gen Intern Med. 2004;19(4):316-23.

47. Romano MJ, Stafford RS. Electronic health records and clinical decision support systems: impact on national ambulatory care quality. Arch Intern Med. 2011;171(10):897-903.

48. Linder JA, Ma J, Bates DW, Middleton B, Stafford RS. Electronic health record use and the quality of ambulatory care in the United States. Arch Intern Med. 2007;167(13):1400-5.

49. Garg AX, Adhikari NK, McDonald H, Rosas-Arellano MP, Devereaux PJ, Beyene J, et al. Effects of computerized clinical decision support systems on practitioner performance and patient outcomes: a systematic review. JAMA. 2005;293(10):1223-38.

50. Chaudhry B, Wang J, Wu S, Maglione M, Mojica W, Roth E, et al. Systematic review: impact of health information technology on quality efficiency, and costs of medical care. Ann Intern Med. 2006;144(10):742-52.

51. O'Connor PJ, Sperl-Hillen JM, Rush WA, Johnson PE, Amundson GH, Asche SE, et al. Impact of electronic health record clinical decision support on diabetes care: a randomized trial. Ann Fam Med. 2011;9(1):12-21.

52. Bates DW, Gawande AA. Improving safety with information technology. N Engl J Med. 2003;348(25):2526-34.

53. Bates DW. Using information technology to reduce rates of medication errors in hospitals. BMJ. 2000;320(7237):788-91.

54. Kuperman GJ, Teich JM, Tanasijevic MJ, Ma'Luf N, Rittenberg E, Jha A, et al. Improving response to critical laboratory results with automation: results of a randomized controlled trial. J Am Med Inform Assoc. 1999;6(6):512-22.

55. Greenes DS, Fleisher GR, Kohane I. Potential impact of a computerized system to report late-arriving laboratory results in the emergency department. Pediatr Emerg Care. 2000;16(5):313-5.

56. Callen J, Paoloni R, Georgiou A, Prgomet M, Westbrook J. The rate of missed test results in an emergency department: an evaluation using an electronic test order and results viewing system. Methods Inf Med 2010;49(1):37-43.
57. Singh H, Naik AD, Rao R, Petersen LA. Reducing diagnostic errors through effective communication: harnessing the power of information technology. J Gen Intern Med. 2008;23(4):489-94.

58. Piva E, Sciacovelli L, Zaninotto M, Laposata M, Plebani M. Evaluation of effectiveness of a computerized notification system for reporting critical values. Am J Clin Pathol. 2009;131(3):432-41.

59. Plebani M. Interpretative commenting: a tool for improving the laboratory-clinical interface. Clin Chim Acta. 2009;404(1):46-51.

60. Couchman GR, Forjuoh SN, Rascoe TG, Reis MD, Koehler B, Walsum KLv. E-mail communications in primary care: what are patients' expectations for specific test results? Int $\mathrm{J}$ Med Inform. 2005; 74(1):21-30.

61. Berg M, Langenberg C, vd Berg I, Kwakkernaat J. Considerations for sociotechnical design: experiences with an electronic patient record in a clinical context. Int $\mathrm{J}$ Med Inform. 1998;52(1-3):243-51.

62. Callen JL, Braithwaite J, Westbrook JI. Contextual implementation model: a framework for assisting clinical information system implementations. J Am Med Inform Assoc. 2008;15(2):255-62.

63. O'Leary KJ, Liebovitz DM, Feinglass J, Liss DT, Evans DB, Kulkarni $\mathbf{N}$, et al. Creating a better discharge summary: Improvement in quality and timeliness using an electronic discharge summary. J Hosp Med. 2009;4(4):219-25.

64. van Walraven C, Seth R, Austin PC, Laupacis A. Effect of discharge summary availability during post-discharge visits on hospital readmission. J Gen Intern Med. 2002;17(3): 186-92.

65. Bolton P, Mira M, Kennedy P, Lahra MM. The quality of communication between hospitals and general practitioners: an assessment. J Qual Clin Pract. 1998;18(4):241-7.

66. Callen J, McIntosh J, Li J. Accuracy of medication documentation in hospital discharge summaries: A retrospective analysis of medication transcription errors in manual and electronic discharge summaries. Int J Med Inform. 2010;79(1):58-64.

67. Berlin L. Communicating results of all outpatient radiologic examinations directly to patients: the time has come. AJR Am J Roentgenol. 2009;192 (3):571-3.

68. Berlin L. Communicating results of all radiologic examinations directly to patients: has the time come? AJR Am J Roentgenol. 2007;189(6):1275-82.

69. Hammerman HJ. Communicating imaging results to patients: OnSite results. AJR Am J Roentgenol. 2009;192(4):852-3.

70. American College of Radiology. ACR Practice Guideline for Communication of Diagnostic Imaging Findings. 2010:1-6. Accessed 12 May 2011. http://www.acr.org/secondarymainmenucategories/quality_safety/ guidelines/dx/comm_diag_rad.aspx. 2010.

71. Kilpatrick ES. Use of computer terminals on wards to access emergency test resutls: a retrospective audit. Br Med J. 2001;322:3

72. Graber $\mathbf{M}$. The physician and the laboratory: partners in reducing diagnostic error related to laboratory testing. Am J Clin Pathol. 2006;126(Suppl 1):S44-7.

73. Unruh KT, Pratt W. Patients as actors: the patient's role in detecting, preventing, and recovering from medical errors. Int $\mathrm{J}$ Med Inform. 2007;76(Suppl 1):S236-44.

74. Wald JS, Burk K, Gardner K, Feygin R, Nelson E, Epstein M, et al. Sharing electronic laboratory results in a patient portal-a feasibility pilot. Stud Health Technol Inform. 2007;129(Pt 1):18-22.

75. Ley P. Memory for medical information. Br J Soc Clin Psychol. 1979;18 (2):245-55.

76. Kessels RP. Patients' memory for medical information. J R Soc Med. 2003;96(5):219-22

77. US Department of Health and Human Services, US Food and Drug Administration. 2004. Mammography Quality Standards Act (MQSA) MAMMOGRAPHY QUALITY STANDARDS ACT (MQSA) (AS AMENDED BY MQSRA of 1998 and 2004).Accessed September, 26, 2011. http://www.fda. gov/Radiation-EmittingProducts / MammographyQualityStandards ActandProgram/Regulations/ucm110823.htm.

78. Priyanath A, Feinglass J, Dolan NC, Haviley C, Venta LA. Patient satisfaction with the communication of mammographic results before and after the Mammography Quality Standards Reauthorization Act of 1998. AJR Am J Roentgenol. 2002;178(2):451-56.

79. Shekelle PG, Pronovost PJ, Wachter RM, Taylor SL, Dy SM, Foy R, et al. Advancing the science of patient safety. Ann Intern Med. 2011;154 (10):693-6.

80. Leape LL, Berwick DM, Bates DW. What practices will most improve safety? Evidence-based medicine meets patient safety. JAMA. 2002;288 (4):501-7.

81. Wachter RM. Why diagnostic errors don't get any respect-and what can be done about them. Health Aff (Millwood). 2010;29(9):1605-10. 


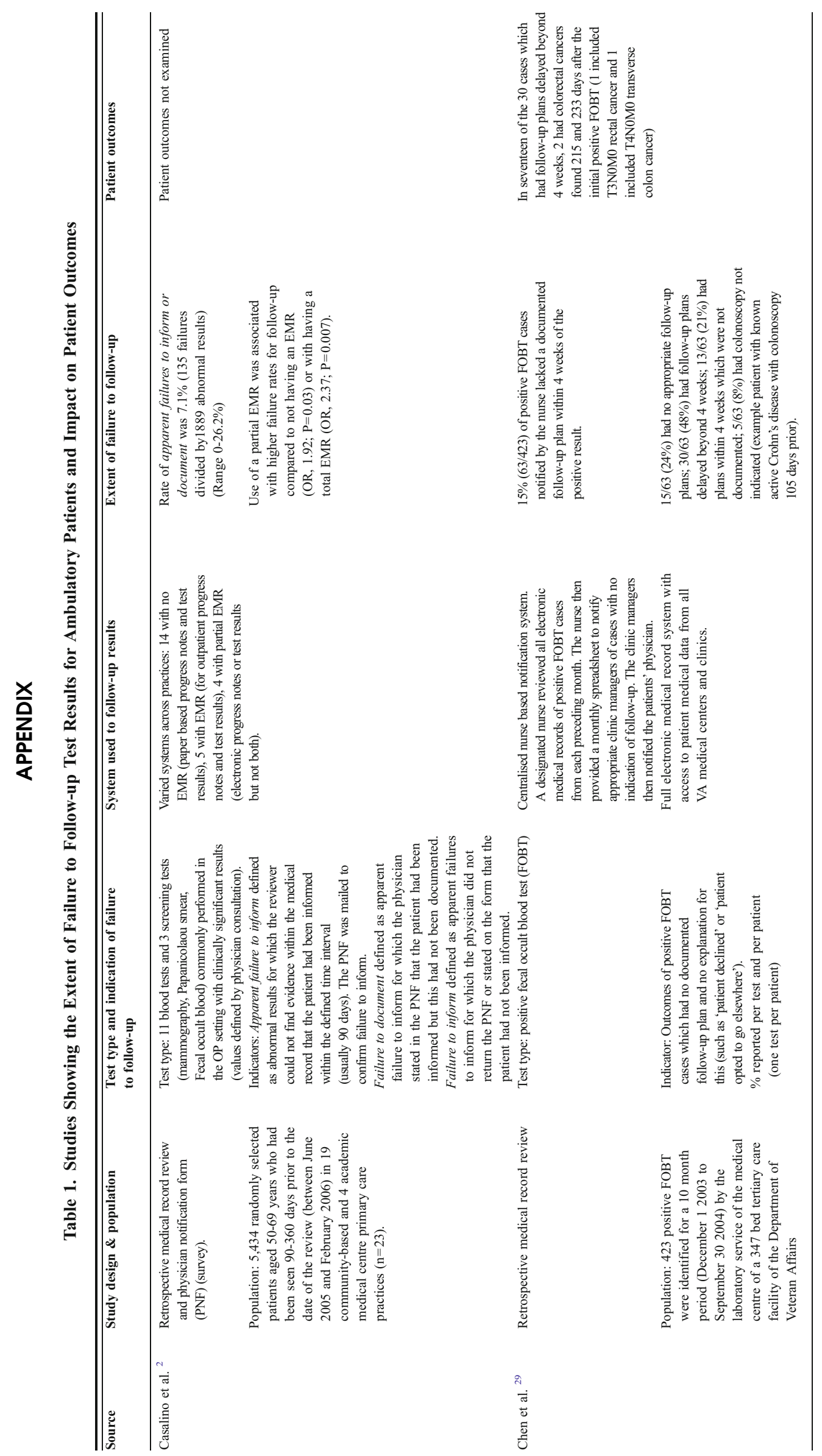




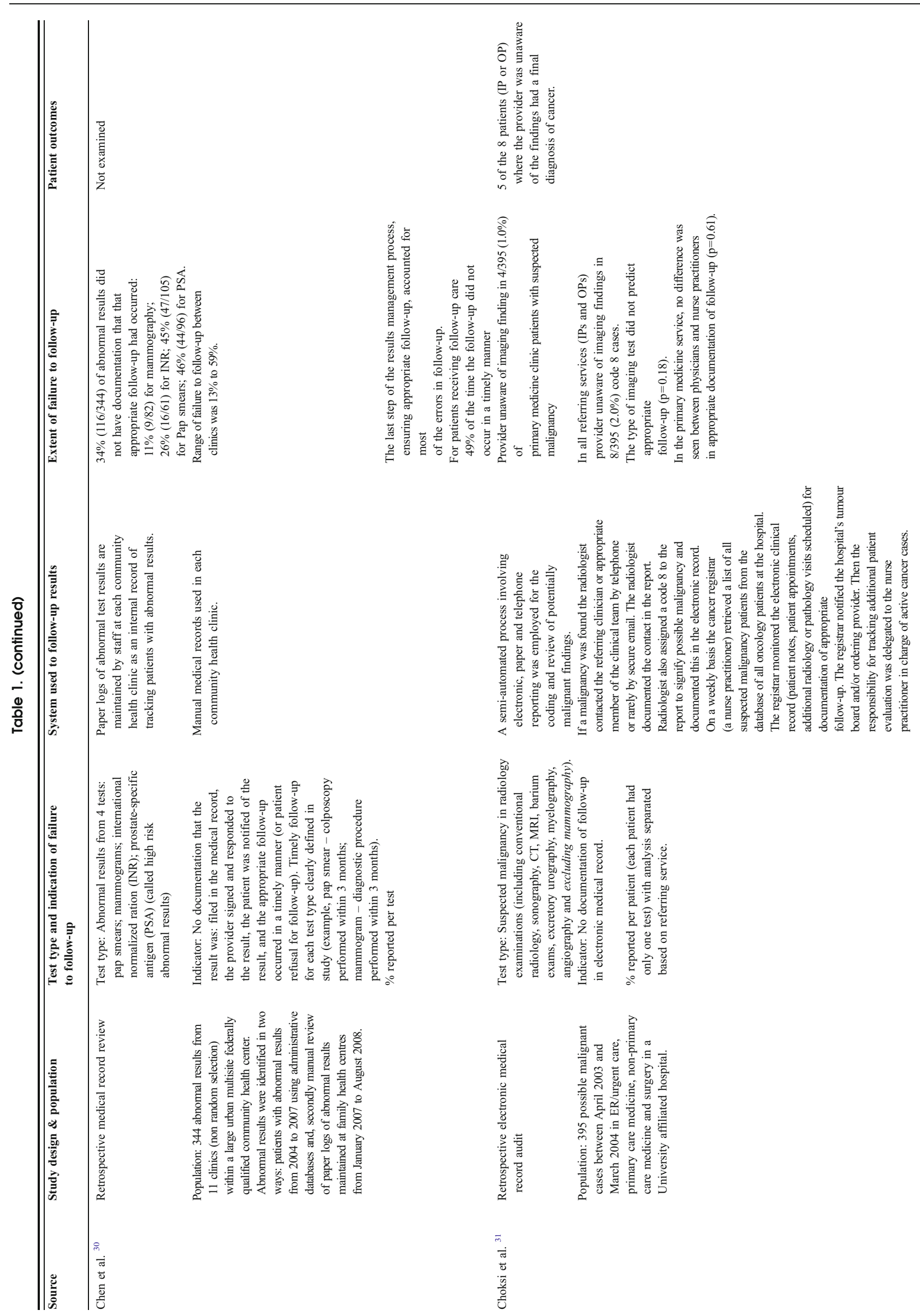




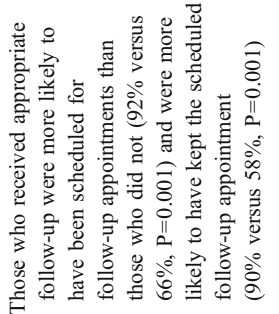

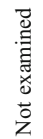

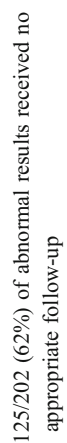
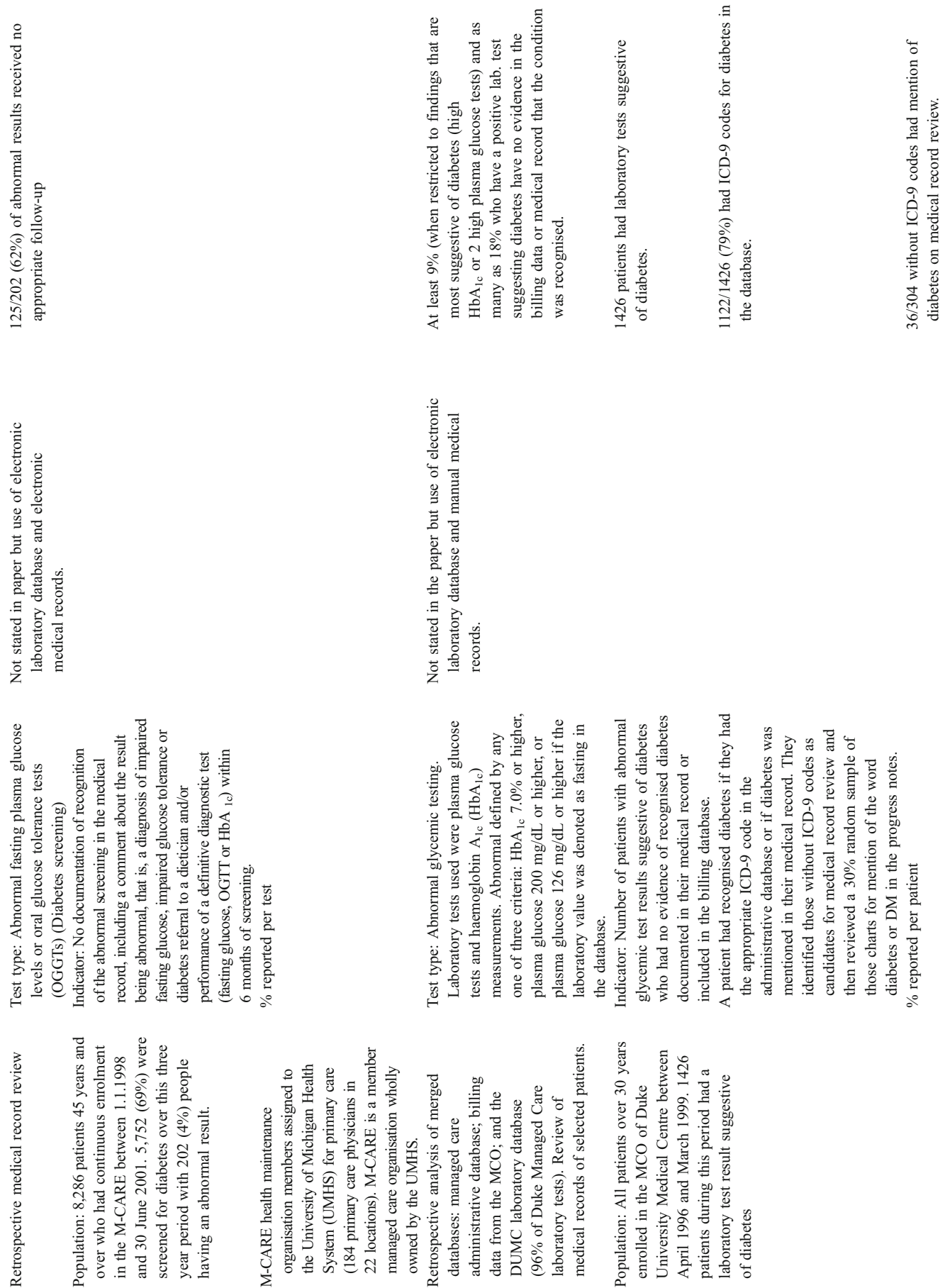


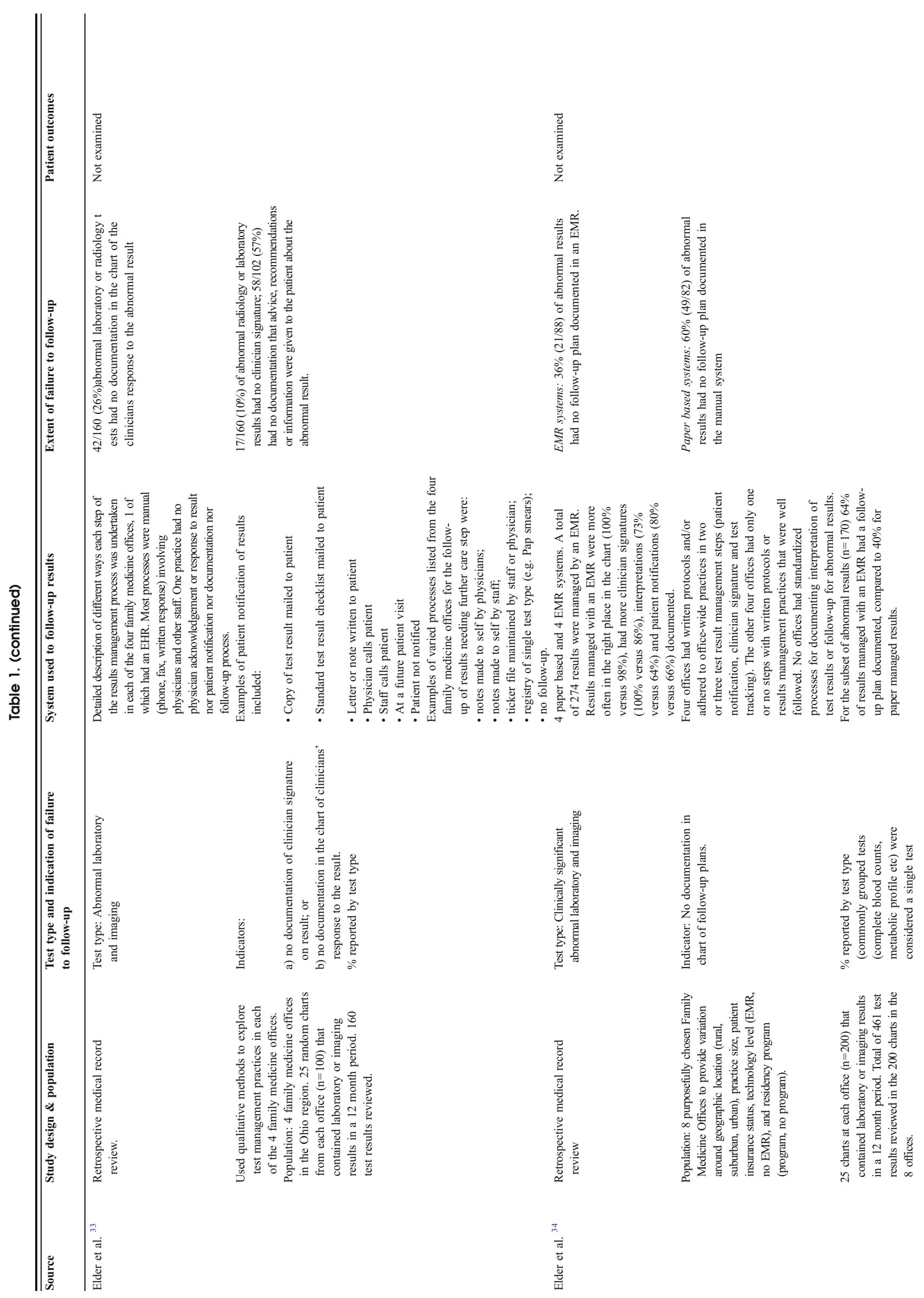




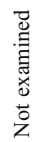

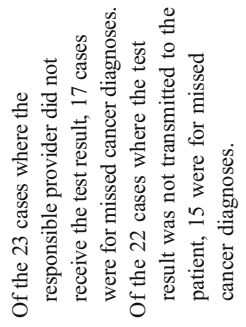

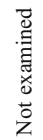

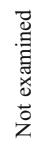

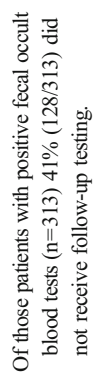
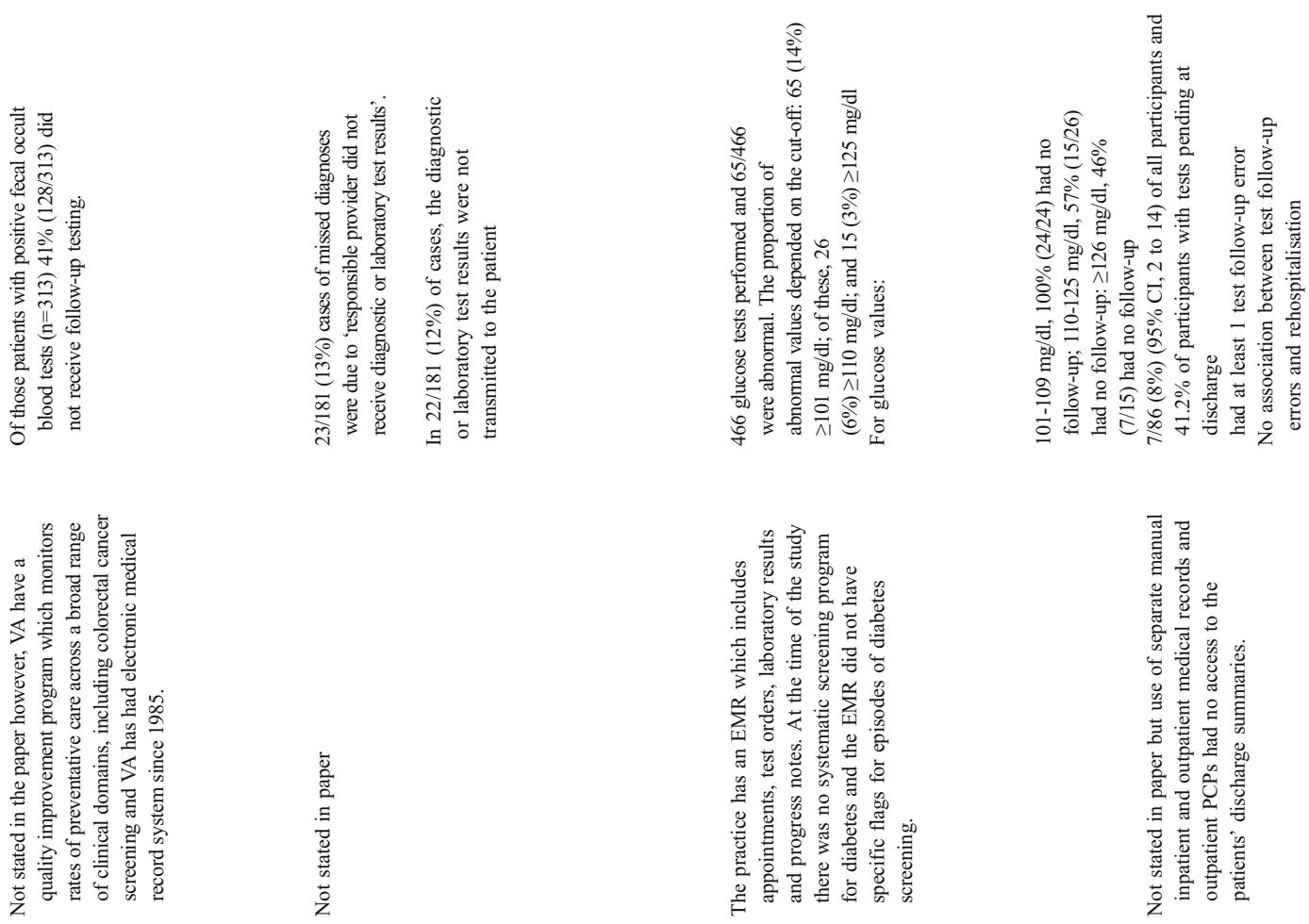

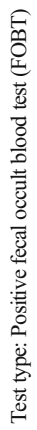
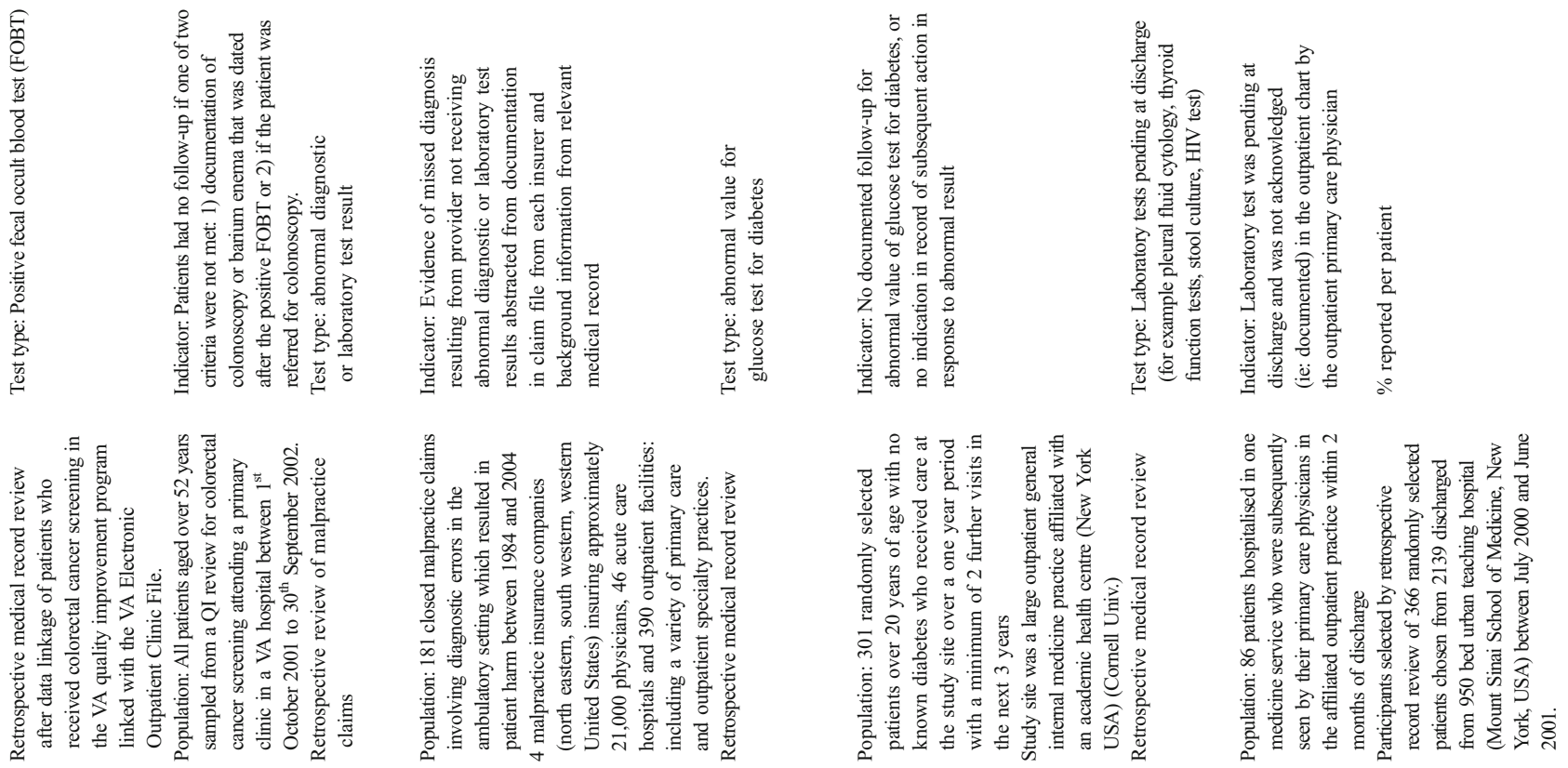

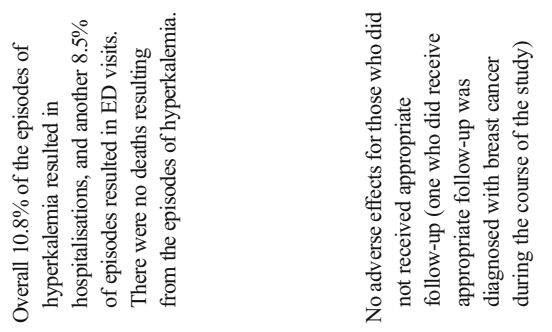

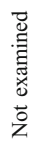
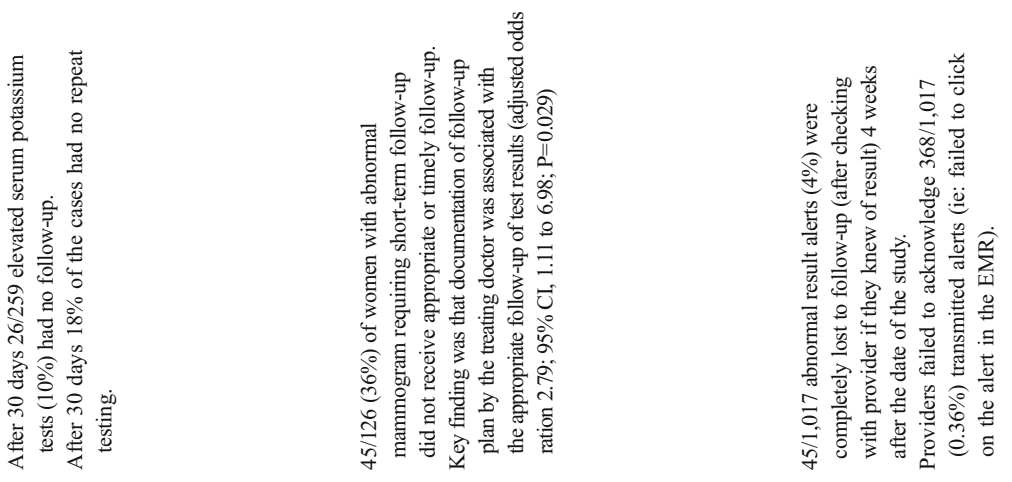

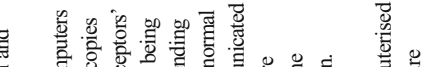

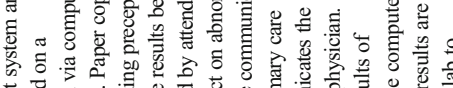

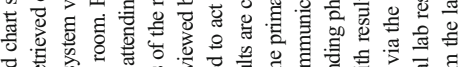

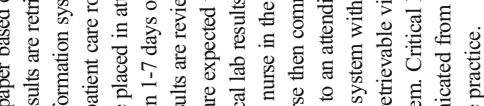

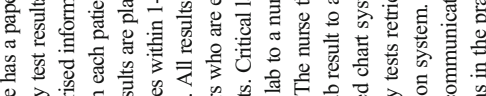

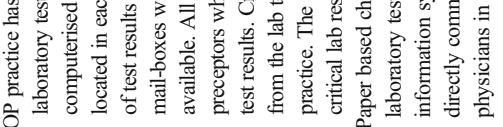

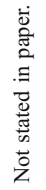

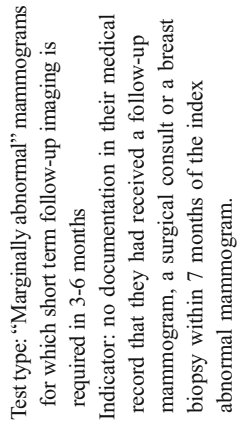

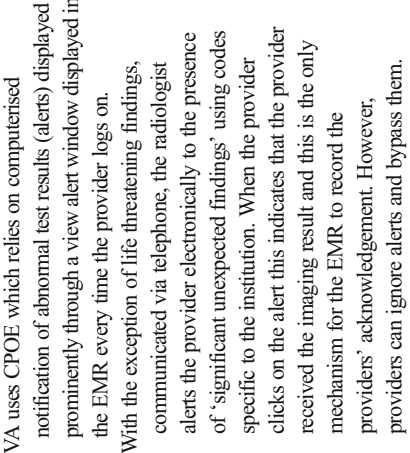

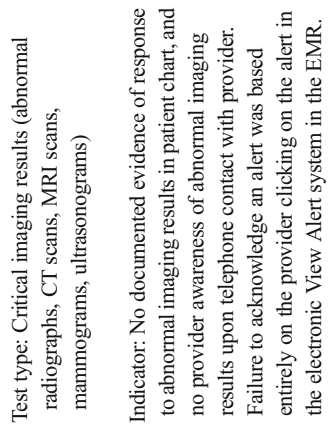

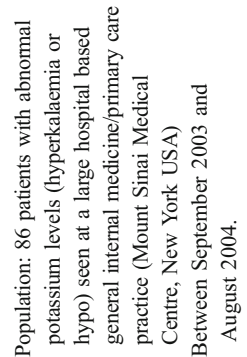

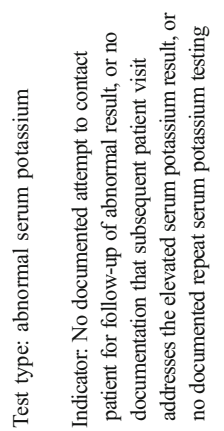

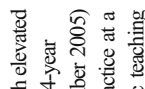

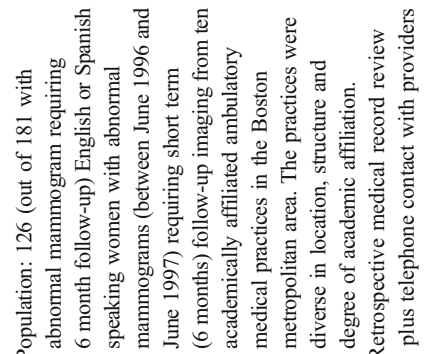

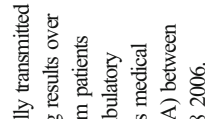

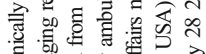

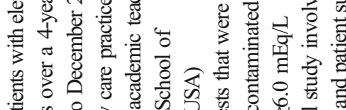

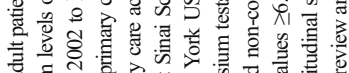

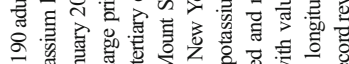

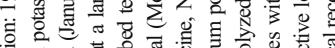

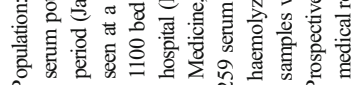

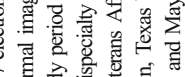

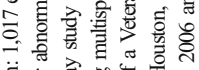

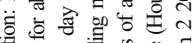

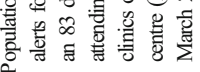




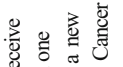

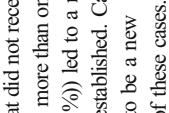

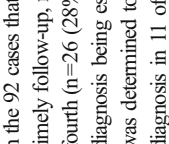

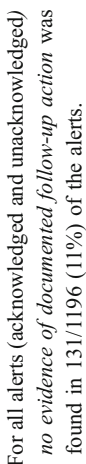

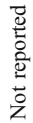

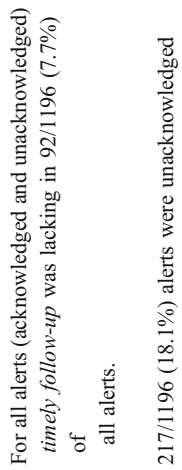

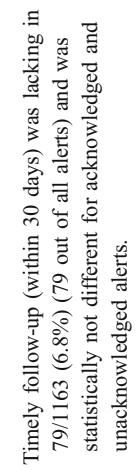
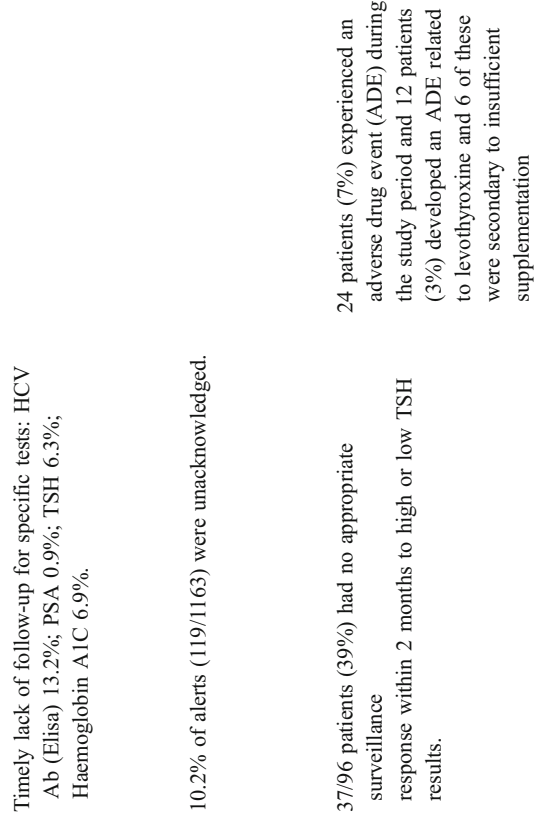
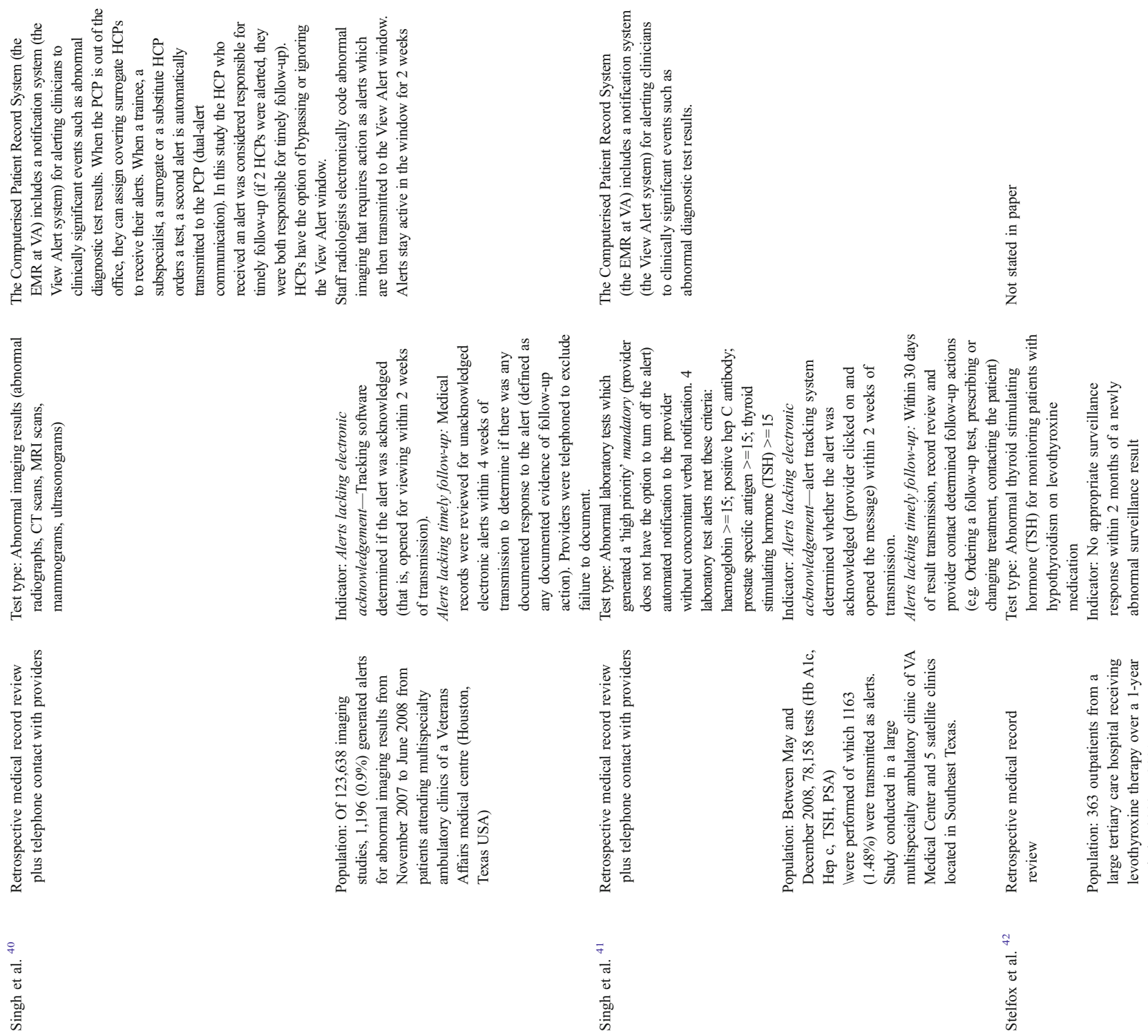